\title{
Factors associated with injuries among first-division Rwandan female soccer players
}

\author{
Niyonsenga JD, *Phillips JS \\ Department of Physiotherapy University of the Western Cape Private Bag X17 Bellville 7535 Ph
}

\begin{abstract}
Background: Female soccer has grown tremendously in the last decade. Studies have suggested that female soccer players are more susceptible to injuries than their male counterparts, and their vulnerability is due mainly to intrinsic factors such as their anatomical and physiological structure.

Objectives: To establish factors associated with soccer injuries among first-division Rwandan female soccer players.

Methods: In a descriptive cross-sectional study, self-administered questionnaires were used to investigate factors associated with injuries among soccer players.

Results: Almost half of the 300 participants (45\%) indicated having been injured in the three seasons prior to the study. More than half $(52.6 \%)$ were recurrent injuries. The ankle was the most common body part injured. Intrinsic factors associated with injuries were age, excessive ankle range of motion, pre-menstrual symptoms, and previous injury ( $\mathrm{p}$-value $<0.05)$. Extrinsic factors associated with injuries were use of oral contraceptive pills, (OCP), competition level, use of protective equipment, and player's position.

Conclusions: The large number of recurring injuries was notable, emphasizing the importance of prevention strategies and access to adequately trained medical personnel as research has shown a significant reduction in the prevalence of recurring injuries after the introduction of effective prevention programmes.
\end{abstract}

Key words: female soccer players, injuries, intrinsic and extrinsic factors

African Health Sciences 2013; 13(4): 1021 - 1026 http://dx.doi.org/10.4314/ahs.v13i4.23

\section{Introduction}

Football, also called "soccer" to distinguish it from American football, is one of the most popular team sports around the world ${ }^{1}$. It is practised in more than 200 countries $^{1}$ and performed by men, women and children at different levels of expertise $e^{2}$. When football first started, it was primarily a sport practised by men, but as it gained popularity, the number of females practising this sport increased, so that by 2008 more than 40 million females were registered worldwide with the International Federation of Football Association (FIFA) ${ }^{3}$. Several studies highlighted the increased rate of soccer injuries proportionally to its increased popularity, but very few included those of female soccer players ${ }^{3,4}$. In most African countries, female and male soccer fall under one national football association, which may have led to delayed development of female soccer.
*Corresponding author:
Phillips S Julie
Department of Physiotherapy
University of the Western Cape
Private Bag X17 Bellville 7535
Ph: +27-21-959 2542
Fax: +27-21-959 1217
E-mail: jphillips@uwc.ac.za

Several studies have suggested that female soccer players are more susceptible to injuries than their male counterparts, and that the injury rate increased proportionally with increased participation ${ }^{5,6}$. The vulnerability of female soccer players is due mainly to intrinsic factors, such as their anatomical and physiological structure ${ }^{5}$. The influence of intrinsic factors relates to age, sex, previous injuries, inadequate rehabilitation, aerobic fitness, body size, limb dominance, flexibility, limb girth, muscle strength, muscle imbalance, reaction time, postural stability, anatomical alignment, foot morphology, and hormonal and menstrual cycle. In contrast, the injuries associated with the extrinsic factors relate to level of competition, level of skill, shoe type, prophylactic use of ankle tape and bracing, and the playing surface ${ }^{6-10}$.

Few studies have been conducted to clarify the factors associated with injuries in female soccer players in Africa ${ }^{4}$. The number of female soccer participants in Rwanda is continuously increasing thanks to the various competitions that are organised in schools at all levels (primary, secondary and tertiary), as well as to competitions played in Provinces and Districts ${ }^{11}$. Rwanda is a member of 
the African Confederation of Football (CAF) and has been affiliated to the International Federation of Football Associations (FIFA) since 1976 ${ }^{12,13}$. Fédération Rwandaise de Football Association (FERWAFA) is the national board controlling soccer for both males and females country-wide in Rwanda. Female soccer is only played in the first division at national level, which consists of 12 teams, and the majority of them originate from urban areas.

Even though the number of participants is extremely low compared to the numbers in developed countries, the rate of injuries related to soccer is extremely high, which might be due to the various intrinsic and extrinsic factors predisposing female players to injuries ${ }^{14}$. Poor rehabilitation and lack of follow-up processes are often responsible for recurrent injuries. Adding to these are negligence and a lack of preventative measures against injuries, a low level of knowledge among soccer trainers, and inadequate high-quality training ${ }^{14}$. Therefore the overall aim of this study was to establish the factors associated with injuries among first-division soccer players. The specific objectives of the study were: to establish the prevalence of injuries among players; to establish the location and re-occurrence of injuries; and to establish the association of selected intrinsic and extrinsic factors with injuries. The injury definition used for this study was "damage to the body sustained during practice or game sessions causing absence from at least the following practice and/or game session"15.

\section{Methods}

\section{Research Design}

A cross-sectional study design using quantitative methods was used to investigate factors associated with sports injuries in first-division Rwandan female soccer players.

Study sample and location

This study was conducted in Rwanda among the first-division female soccer teams. These teams are all similar with regard to the locality of their players as well as the players' age and background. All 12 soccer teams in the first division were approached to participate in the study (23-30 players per team). Prior to approaching teams, ethical clearance was obtained from the UWC Research Grants and Study Leave Committee. Permission was also obtained from the Ministry of Sports in Rwanda, FERWAFA and the soccer team managers of the first-division teams. All teams were contacted at their training camps as the agreed and most convenient time. All participants were informed about the study and asked for their voluntary participation. Written informed consent was given by each participant. The researchers ensured anonymity and confidentiality to all the participants. They were assured that they had the right to withdraw from the study at any time.

Research instrument

A self-administered questionnaire including closed-ended questions, which had been used by researchers in previous research, was used as is to collect data from players ${ }^{6}$. The instrument requested socio-demographic data such as age, occupation, player position, number of years participating in soccer and information regarding previous injuries sustained. Injuries sustained in activities other than soccer games/practice sessions were excluded. Information such as time of injury, mechanism and location of injury was also collected. In addition, use of protective equipment and details regarding menstrual cycles and oral contraceptive use were also requested. The research instruments were translated into French and Kinyarwanda as the commonest languages used by participants, and thereafter, backtranslated by two independent translators to further enhanced the validity and reliability of the instrument. The questionnaire was then sent to experts in the field of female soccer injuries, to ensure content validity. To ensure that the instrument was reliable, a pilot study with 20 female soccer players participating at the provincial level was conducted. The instrument was re-administered to the same group of players two weeks later, to check its consistency.

\section{Procedures}

The researchers and trained research assistants commenced with the data collection subsequent to permission being granted. Each team was visited twice; the first day was used to explain the procedure, and clarify and distribute the questionnaires. On the second day, range of motion of the knee and ankle and measurements of height and weight was done and recorded. In addition questions from the participants were answered, players were referred for follow-up medical and related attention, and preventative and rehabilitative advice were given.

The research assistants were qualified physiotherapists. All research assistants received training with regards to measurements of height, weight and range of motion to ensure standardized procedures. The body weight and height of each player were measured and recorded. Joint range of motion of the knee and ankle was also measured 
with the use of a goniometer. Knee extension was measured with the participants sitting on the edge of the table with the popliteal fossa away from it and their legs dangling free. One hand grasped the leg at the ankle joint and the other hand in the popliteal fossa to act as a fulcrum and unlock the knee. Ankle dorsiflexion was also measured in the same starting position as with knee range of motion. In this position the gastrocnemius is relaxed and is eliminated as possible restriction of dorsiflexion. To ensure that ankle motion alone takes place, the forefoot was inverted to look it into the hind-foot. Passive ankle dorsiflexion of more than 30 degrees and passive knee extension of more than 10 degrees were chosen as a measure of excessive range of motion $^{16}$.

\section{Data analysis}

Data was analysed using the Statistical Package for Social Sciences (SPSS) version 18.0. Descriptive statistics were employed to summarise data used in the study. These consisted mainly of frequencies, percentages, means and standard deviations. Inferential statistics such as cross-tabulations were used to test for significant associations between selected factors and injuries. The chi-square test was used to test for association between injury status (injured versus non-injured) and hypothesised factors at the $5 \%$ level of significance $(<0.05)$.

\section{Results}

The Spearman's correlation coefficient for the testretest reliability of the instruments ranged between .927 and 1.00. This score as strong enough to ensure validity and reliability of the instrument.

\section{Characteristics of the study sample}

A total of 300 first-division soccer players participated in the study, i.e. $100 \%$ response rate. The mean age of the participants was 20.02 years $(S D=3.138)$. The mean number of years that participants had played soccer was 4.3 years $(\mathrm{SD}=3.288)$. The distribution of the players was as follows: goalkeepers $(8 \%, \mathrm{n}=24)$; defenders $(22.3 \%$, $\mathrm{n}=67)$, midfielders $(31.3 \%, \mathrm{n}=94)$ and strikers $(38.4 \%, n=115)$.
Table 1: Selected intrinsic factors associated with injuries $(n=300)$

\begin{tabular}{|c|c|c|c|}
\hline Variable & $\begin{array}{c}\text { Injured } \\
(\%)\end{array}$ & $\begin{array}{l}\text { Non- } \\
\text { injured }(\%)\end{array}$ & $\begin{array}{l}\text { Significance } \\
\text { ()) }\end{array}$ \\
\hline \multicolumn{3}{|l|}{ Age (in years) } & \multirow[t]{5}{*}{$\mathrm{p}=0.000$} \\
\hline $14-17$ & 3.0 & 22.3 & \\
\hline $18-21$ & 27.0 & 14.0 & \\
\hline $22-25$ & 14.0 & 16.0 & \\
\hline$>25$ & 1.0 & 2.7 & \\
\hline \multicolumn{3}{|l|}{ BMI (kg.m $\left.{ }^{-2}\right)$} & \multirow{4}{*}{$\mathrm{p}=0.105$} \\
\hline$<18.5$ & 0.0 & 1.3 & \\
\hline $18.5-24.99$ & 44.7 & 53.7 & \\
\hline$>25.0$ & 0.3 & 0.0 & \\
\hline \multicolumn{3}{|c|}{ Previous injury } & \multirow[t]{3}{*}{$\mathrm{p}=0.000$} \\
\hline Yes & 23.7 & 0.0 & \\
\hline No & 21.3 & 0.0 & \\
\hline \multicolumn{3}{|c|}{ Pre-menstrual symptoms } & \multirow[t]{3}{*}{$\mathrm{p}=0.000$} \\
\hline Yes & 25.0 & 13.3 & \\
\hline No & 20.0 & 41.7 & \\
\hline \multicolumn{3}{|c|}{ Oral Contraceptive Pill use } & \multirow[t]{3}{*}{$\mathrm{p}=0.037$} \\
\hline Yes & 28.1 & 71.9 & \\
\hline No & 47.1 & 53.0 & \\
\hline \multicolumn{3}{|c|}{ Knee range of motion } & \multirow[t]{3}{*}{$\mathrm{p}=0.037$} \\
\hline$<10$ degrees & 38.0 & 50.7 & \\
\hline$>10$ degrees & 7.0 & 4.3 & \\
\hline \multicolumn{3}{|c|}{ Ankle range of motion } & \multirow[t]{3}{*}{$\mathrm{p}=0.006$} \\
\hline$<30$ degrees & 41.7 & 54.3 & \\
\hline$>30$ degrees & 3.3 & 0.7 & \\
\hline
\end{tabular}

Injuries sustained by study sample

Participants were requested to report on injuries sustained in the last three seasons prior to the study. Almost half of the participants $(45 \%, \mathrm{n}=135)$ indicated having been injured. Of the injuries sustained, $46.7 \%$ occurred during training and 53.3\% during competition sessions. Of the total injuries, more than half $(52.6 \%, \mathrm{n}=71)$ were recurrent injuries. The ankle was the most common body part injured $(23.7 \%, \mathrm{n}=32)$ followed by the knee $(14.8 \%, \mathrm{n}=20)$ and thigh $(14.1 \%, \mathrm{n}=19)$.

The Chi-square test was used to ascertain if there was a significant relationship between injury and selected factors. The results are presented in tables 1 and 2 for selected intrinsic and extrinsic risk factors respectively. The intrinsic factors associated with injuries were age, excessive ankle range of motion, pre-menstrual symptoms, and previous injury ( $\mathrm{p}$-value $<0.05$ ). Players in the age group 18 21 years, those with excessive ankle range of motion and those who have sustained an injury before were more likely to report an injury than those in other 
age groups, with normal ankle range of motion and those with no previous injuries. The extrinsic factors associated with injuries were the use of OCP, competition level, use of protective equipment, player's position, preventative measurements such as cool down and skills training, and being a member of the national team. Players who cooled down after training or matches, who used protective equipment, were less likely to sustain an injury than those who did not cool down after training or matches or that did not use protective equipment. In addition, players who were a member of the national squad were more likely to report an injury than those who were not a member of the national squad.

Table 2: Selected extrinsic factors associated with injuries $(n=300)$

\begin{tabular}{|c|c|c|c|}
\hline Variable & $\begin{array}{l}\text { Injured } \\
(\%)\end{array}$ & $\begin{array}{l}\text { Non- } \\
\text { injured } \\
(\%)\end{array}$ & Significance \\
\hline \multicolumn{3}{|l|}{ Cool down } & \multirow[t]{3}{*}{$\mathrm{p}=0.049$} \\
\hline Yes & 39.3 & 60.7 & \\
\hline No & 50.7 & 49.3 & \\
\hline \multicolumn{3}{|c|}{ Skills training } & \multirow[t]{3}{*}{$\mathrm{p}=0.001$} \\
\hline Yes & 39.0 & 61.0 & \\
\hline No & 59.8 & 40.2 & \\
\hline \multicolumn{3}{|c|}{ Use of shin guards } & \multirow[t]{6}{*}{$\mathrm{p}=0.000$} \\
\hline Yes & 39.1 & 60.9 & \\
\hline No & 81.0 & 19.0 & \\
\hline \multicolumn{3}{|l|}{ Joint supports } & \\
\hline Yes & 22.6 & 77.4 & \\
\hline No & 53.7 & 46.3 & \\
\hline \multicolumn{3}{|c|}{ Training vs match } & \multirow[t]{3}{*}{$\mathrm{p}=0.000$} \\
\hline Training & 21.0 & 79.0 & \\
\hline Match & 24.0 & 76.0 & \\
\hline \multicolumn{3}{|c|}{ Member of national squad } & \multirow[t]{3}{*}{$\mathrm{p}=0.001$} \\
\hline Yes & 84.0 & 16.0 & \\
\hline$\underline{\text { No }}$ & 41.5 & 58.5 & \\
\hline
\end{tabular}

\section{Discussion}

That soccer is viewed as an increasingly popular sport for women is well established ${ }^{6}$. These authors further alerted us to the famous quote of Sep Blatter that the future of football is feminine. They, however, stated that the demands of the game and the potential injuries should not be underestimated, and that these injuries must be managed appropriately to ensure that young female soccer players have a future in this sport. This current study highlighted the high number of injuries sustained by female soccer players in Rwanda (45\%). Although caution should be exercised when comparing this with other studies because of the differing injury definitions, it appears that the prevalence in this study is similar to studies elsewhere ${ }^{3}$. However, some researchers ${ }^{17}$-stress the importance of studies like the current one, as they argue that descriptive studies are important in identifying injury patterns among female soccer players. Researchers ${ }^{4}$ also stress the importance of all future studies to use the consensus statement of Fuller et al. (2006) ${ }^{18}$ with regard to injury definition and methods of data collection.

The majority of injuries in this study were found to be in the lower limbs, consistent with the findings of numerous other studies ${ }^{3,4,8,19}$. Mtshali et al. $(2009)^{3}$ are of the opinion that the higher number of ankle and knee injuries could be attributed to cutting, jumping and landing, skills that are different for female soccer players. These authors further postulate that the ankle is the main point of contact in soccer, and is therefore more prone to be injury. Others ${ }^{20}$ have posed that joint laxity could be a significant predictor of lower limb injuries in female soccer players.

More than half $(52.6 \%)$ of the injuries reported in this study were recurrent. This is similar to the findings reported by other researchers ${ }^{21}$. Recurrence of injuries could also be due to inadequate rehabilitation of previous injuries ${ }^{20}$. Furthermore, some injuries might be not be regarded as serious by either the player or the coach, leading to premature return to sport after initial injury ${ }^{20}$. These findings therefore highlight the importance of proper rehabilitation programmes for soccer injuries to prevent the recurrence of injuries. Research has shown a significant reduction in the prevalence of recurrent injuries after the introduction of a prevention programme for players who have sustained injuries ${ }^{22}$. It is clear that not only is proper rehabilitation important but also the identification of injured players and prevention programmes for such players. The opinion that evidence-based physical tests should be used to determine if players are ready to return to the sport also exist ${ }^{21}$. This would therefore require access to adequately trained medical personnel, and their presence at both games and practice sessions. They further emphasise the importance of access to a sports medicine-trained physiotherapist during pre-season training, as they could play a valuable role in the management of acute injuries and in the provision of sport-specific rehabilitation to the players. The total absence of medical personnel at games and practice sessions of 
all the participating teams in the current study is thus a great cause of concern and should be addressed by the Fédération Rwandaise de Football Association.

The use of protective equipment has been shown to effectively decrease the occurrence of injuries in soccer, by controlling unwanted movements in joints ${ }^{23}$. The non-use of protective equipment was strongly associated with the occurrence of injuries in this study. Female soccer players in this study hardly ever use joint support, and obviously should be encouraged to do so.

Players who were members of the national team reported a significantly higher number of injuries than those who were not part of the national team. This is similar to the findings of Jacobson and Tegner (2007) who argued that this could be caused by the higher exposure to soccer when part of a national team. Selection for the national team increases not only the exposure time, but also the level of competition and fatigue. In addition, the level of competition appears to be more aggressive at this level, and the desire to keep a place in the national team should not be ignored.

\section{Conclusion}

This study has emphasised the high incidence of injuries among female soccer players and considered the factors associated with injury. The large number of recurring injuries was notable, and emphasised the importance of prevention strategies and access to and presence of adequately trained medical personnel.

\section{Limitations of the study}

It is recognized that the design of this study is a limitation as recall bias (three competitive seasons) could influence the reliability of the injury prevalence. It has been debated that prospective designs are more reliable for injury prevalence unlike retrospective designs that tend to be limited due to recall bias. However, since no studies have been done before to determine the prevalence of soccer injuries amongst female soccer players in Rwanda, this retrospective study would give an idea of the magnitude of the problem. Furthermore, since this study aimed to give an idea of the magnitude of the problem, it did not investigate the intrinsic factors associated with injuries in depth. In addition if exposure time was measured, it would have been possible to compare with similar international studies.
Future research should therefore focus on intrinsic predisposing factors to injury to provide a more comprehensive description of these factors.

\section{References}

1. Fédération Internationale de Football Association (FIFA) (2008). Associations. Available at: http://www.fifa.com/ aboutfifa/federations/associ ations.html. Accessed on 20 May, 2010.

2. Bangsabo J. The physiology of soccer: with special reference to intense intermittent exercises. Acta Physiologica 1994; 15(619): 1-159.

3. Tegnander A, Olsen OE, Mohaldt T'T, Engebretsen L, Bahr R. Injuries in Nowergian female elite soccer: a prospective one season cohort study. Knee Surgery, Sports Traumatology, Arthroscopy 2008; 16(2): 194-198.

4. Mtshali P, Mbambo-Kekana N, Stewart A, Musenge E. Common lower extremity injuries in female high school soccer players in Johannesburg East District. South African Journal of Sports Medicine 2009; 21: 163-166.

5. Silberberg SL. Anterior Cruciate Ligament in Female Soccer Players. Hughston, California, 2010.

6. Bennet P, Fawcett L. Trauma injuries sustained by female footballers. Trauma, 2006; 8: 69-76.

7. Biedert RM, Bechmann M. Women's soccer injuries, risks and prevention. Del Orthopade, 2005; 34(5): 448-453.

8. Giza E, Mithofer K, Farrell L Zarins B, Gill T. Injuries in women's professional soccer. British Journal of Sports Medicine, 2005; 39:212-216.

9. Murphy DF, Connolly DAJ, Beynno BD. Risk factors for lower extremity injury: a review of the literature. British Journal of Sports Medicine, 2003, 37(1): 13-29.

10. Beynnon B, Murphy D, Alosa D. Predictive factors for lateral ankle sprains: A literature review. Journal of Athletic Training, 2002; 37(4): 376-380.

11. Fédération Rwandaise de Football Association (FERWAFA), (2010). Female soccer in Rwanda. FERWAFA report. 
12. Confederation of African Football (CAF). (2004). African football championships.

Retrieved on April the 20th, 2010 from http://www.cafonline.com/competition/ caf_competitions nations cup/index.htm

13. Fédération Internationale de Football Association (FIFA), (2003). National Associations. Retrieved on April the 20th, 2010 from http://apps.fifa.com/scripts/ runisa.dll?m2:g p $67173+$ assoc/ home $+\mathrm{E}+\mathrm{CAF}+\mathrm{RW}$

14. Hakizimana M. Football sports injuries and their management in Rwanda. Unpublished Research Project, Kigali Health Institute, Rwanda, 2002.

15. Orchard JW. Intrinsic and extrinsic factors for muscle strains in Australian football. The American Journal for Sports Medicine, 2001; 29(3): 300-305.

16. Carter C \& Wilkinson J. Persistent joint laxity and congenital dislocation of hip. British Journal of Bone and Joint surgery, 1964; 6: 4045.

17. Söderman, K, Adolphson, J, Lorentzon R, Alfredson H. Injuries in adolescent female players in European ootball: a prospective study over one outdoor soccer season Scandinavian Journal of Medicine and Science in Sports 2001; 11: 299-304.

18. Fuller C, Ekstrand J, Junge A, Andersen T, Bahr R, Dvorak J, Hägglund Met al. Consensus statement on injury definitions and data collection procedures in studies of football (soccer) injuries. British Journal of Sports Medicine 2006; 16(2):97-106.

19. Emery CA, Meeuwisse WH. Risk factors for injury in indoor compared with outdoor adolescent soccer. American Journal of Sports Medicine 2006; 34(10):1636-1644.

20. Soderman, K., Alfredson, H., Pietila, T., \& Werner S. (2001). Risk factors for leg injuries in female soccer players: a prospective investigation during one out-door season. Knee Surgery, Sports Traumatology, Arthroscopy, 9(5), 313-321.

21. Jacobson I. \& Tegner Y. Injuries among Swedish female elite football players: a prospective population. Scandinavian Journal of Medicine Science and Sports 2007; 17(1): 8491.

22. Bahr R, Lian $\varnothing$, Bahr I. A two-fold reduction in incidence of acute ankle sprains in volleyball after the introduction of an injury prevention program: a prospective cohort study. Scandinavian Journal of Medicine Science and Sports 1997; 7(3):172177.

23. Sharpe SR, Knapik J, Jones B. Ankle braces effectively reduce recurrence of ankle sprains in female soccer players. Journal of Athletic Training 1997; 32(1): 21-24. 